\title{
A rare form of chronic granulomatous disease (type IVA) presenting as inflammatory bowel disease
}

\author{
FRANCISCO A SYLVESTER MD
}

FA SYLVESTER. A rare form of chronic granulomatous disease (type IVA) presenting as inflammatory bowel disease. Can J Gastroenterol 1996;10(4):221-224. Neutrophil dysfunction syndromes can sometimes mimic the clinical and pathological features of inflammatory bowel disease. The case of a 3.5-year-old boy with chronic diarrhea, abdominal pain, poor growth since infancy and microcytic, hypochromic anemia is presented. After an extensive diagnostic evaluation, he was found to have a rare variant (type IVA) of chronic granulomatous disease. His gastrointestinal symptoms markedly improved during therapy with gammainterferon. Chronic granulomatous disease can present initially with a clinical picture suggestive of chronic intestinal inflammation. Therefore it should be considered in the differential diagnosis of atypical inflammatory bowel disease, both in children and young adults.

Key Words: Chronic granulomatous disease, Inflammatory bowel disease
Forme rare de maladie granulomateuse chronique (de type IVA) à l'aspect de maladie inflammatoire de l'intestin

RÉSUMÉ : Les syndromes de dysfonction des neutrophiles simulent parfois les caractéristiques cliniques et pathologiques de la maladie inflammatoire de l'intestin. Cet article présente le cas d'un garçonnet de 3,5 ans présentant une diarrhée et des douleurs abdominales chroniques et une croissance médiocre depuis sa naissance. Après une évaluation diagnostique approfondie, on a découvert chez lui une rare forme de maladie granulomateuse chronique (de type IVA). Ses symptômes digestifs se sont nettement améliorés durant le traitement par gamma-interféron. La maladie granulomateuse chronique peut se présenter au départ par un tableau clinique évocateur d'une inflammation intestinale chronique. Il faut donc envisager cette possibilité lors du diagnostic différentiel d'une maladie intestinale inflammatoire atypique, chez les enfants comme chez les adultes.
Thoorn disorders of neutrophil function, including chronic granulomatous disease (CGD) and glycogen storage disease type $\mathrm{Ib}$, can present with chronic inflammatory lesions in the intestinal tract that can mimic both ulcerative colitis $(1,2)$ and Crohn's disease (3-7). In CGD, phagocytes are unable to kill catalase-producing microorganisms that do not form hydrogen peroxide because of their inability to produce reactive oxygen intermediates, resulting in septic complications and the formation of granulomata and abscesses (8). We report a 3.5-year-old boy who was referred to our hospital with the presumptive diagnosis of inflammatory bowel disease (IBD). He was extensively investigated and ulti- mately diagnosed to have the rare type IVA variant of CGD. Colitic symptoms subsequently abated during therapy with gamma-interferon (9). Because of important therapeutic implications, disorders of neutrophil function such as CGD should be considered in the differential diagnosis of IBD presenting in young patients.

\section{CASE PRESENTATION}

A 3.5-year-old Caucasian boy was referred with a history of chronic diarrhea, midabdominal pain and poor growth since infancy. His stools were soft or watery, with blood and mucus on several occasions. Abdominal pain occurred al-

Division of Gastroenterology $\mathcal{E}$ Nutrition and Research Institute, The Hospital for Sick Children and the University of Toronto, Toronto, Ontario

Correspondence and reprints: Dr FA Sylvester, Hartford Hospital, Division of Pediatric Gastroenterology and Nutrition, 80 Seymour Street,

PO Box 5037, Hartford CT 06102-5037, USA. Telephone 860-545-2053, fax 860-545-1510, e-mail 74733.2415@compuserve.com

Received for publication April 5, 1995. Accepted August 14, 1995 


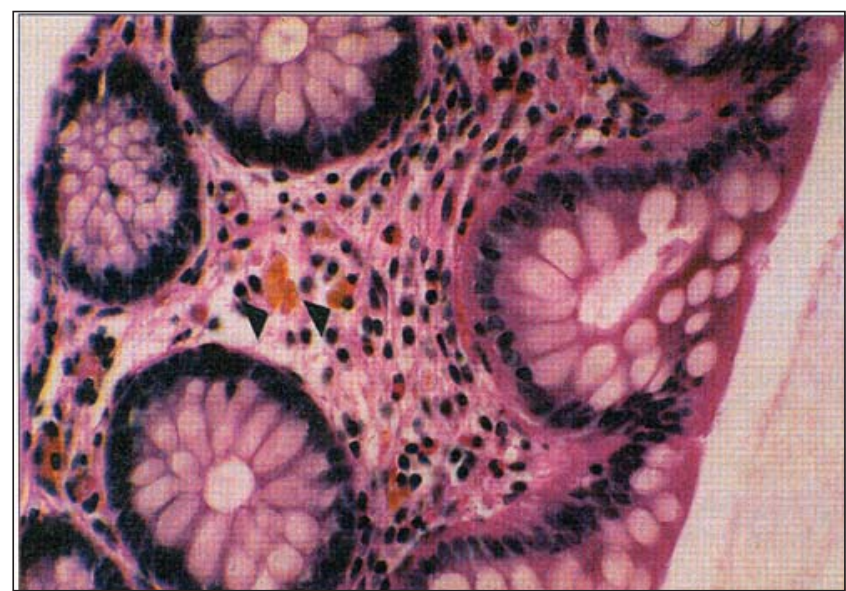

Figure 1) Colonic biopsy (hematoxylin and eosin x193) showing mild to moderate inflammation in the lamina propria. Note occasional pigmented histiocytes (arrowheads)

most daily and woke him up at night. Pruritus was often associated with nocturnal abdominal pain. There was no history of fever. He had a previous history of frequent vomiting, which had recently abated. Previous medical history included bullous impetigo as a neonate, left otitis media at 13 months and cervical adenitis due to Staphylococcus aureus at 14 months of age. A chronic hypochromic, microcytic anemia and leukocytosis had been identified. In the referring hospital an abdominal computed tomography (CT) scan revealed intra-abdominal lymphadenopathy that was biopsied in a diagnostic laparotomy and felt to be 'reactive' histopathologically. A wedge liver biopsy taken at the same time was reported to be normal. Family history was unremarkable. A nitroblue tetrazolium (NBT) test had been reported as normal.

The patient's height was $89 \mathrm{~cm}$ and his weight was $12.2 \mathrm{~kg}$ (both below the third percentile for age). He was a well looking, small, active boy, who was not jaundiced. He had a geographic tongue and finger clubbing. The child had no lymphadenopathy. Chest and cardiovascular examinations were normal. His abdomen was soft, and his liver was felt at 2 $\mathrm{cm}$ below the right costal margin and was firm. There was no palpable spleen. Stool was positive for occult blood and smear revealed a moderate number of leukocytes.

Laboratory evaluation showed hemoglobin of $98 \mathrm{~g} / \mathrm{L}$ with a mean cell volume (MCV) of $59.7 \mathrm{fL}$, platelet count of $611 \times 10^{9} / \mathrm{L}$ and white blood cell count of $25.3 \times 10^{9} / \mathrm{L}(17.2$ polymorphs, 0.51 bands, 1.27 eosinophils, 4.55 lymphocytes, 1.77 monocytes). Erythrocyte sedimentation rate was 16 $\mathrm{mm} / \mathrm{h}$. Ferritin was $21.5 \mathrm{mg} / \mathrm{L}$, and folate and vitamin $\mathrm{B}_{12}$ levels were normal. Aspartate aminotransferase was $35 \mathrm{U} / \mathrm{L}$, alanine aminotransferase $12 \mathrm{U} / \mathrm{L}$, alkaline phosphatase 170 $\mathrm{U} / \mathrm{L}$ and total bilirubin less than $18 \mu \mathrm{mol} / \mathrm{L}$. Albumin was 40 $\mathrm{g} / \mathrm{L}$. Bacterial cultures of the stool and investigations for ova and parasites were negative $(\mathrm{x} 3)$. Immunoglobulins were slightly elevated or normal: immunoglobulin (Ig) G $16.4 \mathrm{~g} / \mathrm{L}$ (normal 5.3 to 16.8 ), $\operatorname{IgA} 1.44 \mathrm{~g} / \mathrm{L}$ (normal 0.2 to 1.2 ), IgM $1.29 \mathrm{~g} / \mathrm{L}$ (normal 0.3 to 2.2 ) and $\mathrm{IgE} 204 \mathrm{ng} / \mathrm{mL}$ (normal 0 to

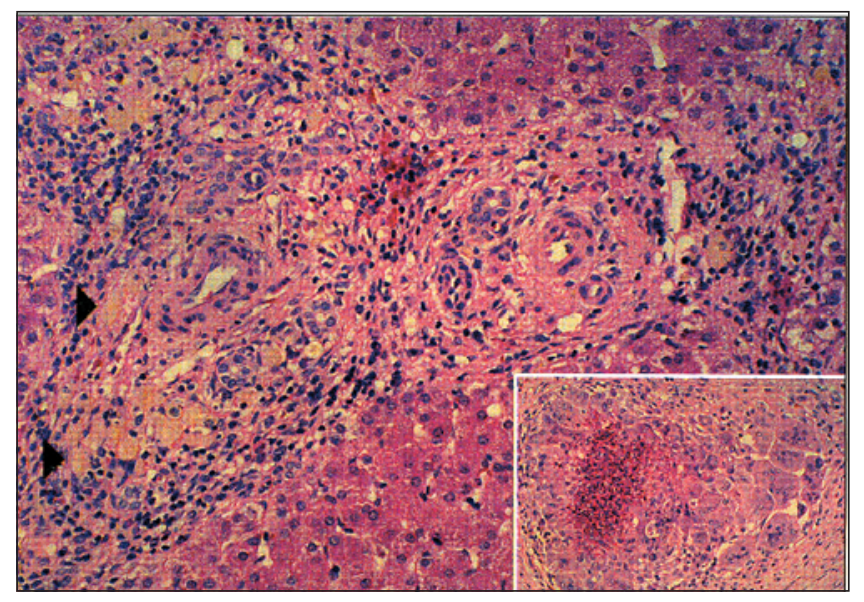

Figure 2) Wedge liver biopsy (hematoxylin and eosin x193). Pigmented histiocytes can be seen in a portal area (arrowheads). Inset shows noncaseating granuloma in another area of the same biopsy specimen

242). Prothrombin time and partial thromboplastin time were normal.

Further investigation of suspected chronic IBD was undertaken. An upper endoscopy was performed. The esophagus and duodenum were normal, with the exception of slightly thickened antral folds. Biopsies revealed minimal nonspecific changes, including occasional histiocytes which contained a small quantity of yellow-brown pigment. A colonoscopy was macroscopically normal, but biopsies showed mild to moderate inflammation with prominence of eosinophils and rare pigmented histiocytes (Figure 1). An abdominal ultrasound revealed a diffuse inhomogeneous echo along the superior aspect of the liver. Abdominal CT showed an abnormal soft tissue mass anterior to the liver with irregular lucency, with possible extension to the anterior mediastinum, as well as gastric wall thickening and lymphadenopathy. A second diagnostic laparotomy was performed to look at this mass. There was no invasive mediastinal tumour. However, the liver appeared very fibrotic, and a wedge biopsy showed granulomatous inflammation, liver cell necrosis and significant fibrosis. Large numbers of histiocytes containing yellow-brown pigment were seen (Figure 2) and appeared similar to the cells seen on previous biopsies from the gastrointestinal tract. This pigment had staining characteristics of lipofuscin, namely positive for periodic acid-Schiff stain, Sudan black and oil red 'O' stain, acid-fast and Giemsa, golden fluorescence on unstained sections, and negative for alcian blue and not birefringent. Similar pigmented cells were also observed in lymph nodes obtained during the surgical procedure.

The association of pigmented histiocytes and granulomata in the biopsies prompted the performance of a repeat NBT test, which was abnormal. The diagnosis of CGD was made. More detailed studies of neutrophil function and cytochrome $b_{558}$ spectroscopy were performed in the patient and family members (Table 1). The patient had a uniform population of phorbol-12-myristate acetate (PMA)-stimulated leukocytes reacting weakly to moderately in the NBT test, whereas his mother had a mixed population of white cells, 
one subset reacting normally (strong) and the other reacting similarly to the patient's cells, which revealed her carrier status. Leukocytes obtained from the rest of the family (father and two siblings) had a uniformly normal strong response. The level of cytochrome $b$, one of the major criteria for classification of CGD, was quantified by means of a dithionate reduced minus oxidized difference spectrum (8) and was $14.7 \%$ of control in the present patient (normal range $8 \%$ to $100 \%$ ). Intact cell superoxide production in the patient was $2.5 \%$ to $6.2 \%$ of the control (low). Based on these studies, this patient was classified as type IVA CGD (8). S aureus bacterial killing was about $50 \%$ less than control values (typical for both moderate and severe forms of CGD). Prophylactic cotrimoxazole, ranitidine and thriceweekly gamma-interferon therapy $\left(42 \mu \mathrm{g} / \mathrm{m}^{2}\right)(9)$ were initiated. Gamma-interferon therapy was well tolerated except for intermittent fever. His colitic symptoms and pruritus resolved, and he gained weight. Five years later he remains in remission of colitis and has been infection-free. His white blood cell count is now normal $\left(6.6 \times 10^{9} / \mathrm{L}\right)$, hemoglobin is $13.1 \mathrm{~g} / \mathrm{L}$ and $\mathrm{MCV}$ is $70.9 \mathrm{fL}$. The intra-abdominal lymph nodes have reduced in size as judged by follow-up CT scans. He has continued to complain intermittently of abdominal pain, although overall the episodes of pain are less frequent and less severe. Colonoscopy has not been repeated.

\section{DISCUSSION}

Our patient's presenting symptoms of intermittently bloody chronic diarrhea, abdominal pain, chronic hypochromic microcytic anemia and growth impairment suggested IBD. Classical septic manifestations of CGD were limited to one episode of $S$ aureus lymphadenitis and neonatal bullous impetigo. Initial differential diagnosis included idiopathic ulcerative colitis and Crohn's disease. However, the patient's young age, the finding of a palpable liver and the presence of pigmented histiocytes in the colonic mucosal biopsies and in the liver biopsy associated with granulomata prompted diagnostic investigations that lead to the diagnosis of CGD even though a previous NBT test had been reported as normal.

CGD is an inherited disorder of leukocyte function characterized by the inability of phagocytes to kill organisms that do not form hydrogen peroxide but produce catalase, resulting in the formation of multifocal abscesses and granulomata (8). The production of superoxide via the respiratory burst by phagocytic cells is absent or severely compromised. This reaction is normally catalyzed by reduced nicotinamide adenine dinucleotide phosphate (NADPH) oxidase, an enzymatic complex containing a membrane-bound cytochrome $b_{558}$ and two cytosolic proteins (with molecular weights of $67 \mathrm{kDa}$ and $47 \mathrm{kDa}$ ). Cytochrome $b_{558}$ is a heme-containing heterodimer consisting of a $91 \mathrm{kDa}$ glycosylated heavy chain and a $22 \mathrm{kDa}$ light chain. Cytochrome $b$ can transfer electrons to oxygen, which is reduced to the radical superoxide.

CGD, rather than being a single entity, encompasses a group of biochemically and genetically heterogeneous disorders with clinical similarities. Males are predominantly affected since the majority of cases $(65 \%)$ are an X-linked

\section{TABLE 1}

Results of repeat nitroblue tetrazolium (NBT) test and cytochrome $b_{558}$ spectroscopy performed in the patient and family members

\begin{tabular}{|c|c|c|c|c|}
\hline \multirow[b]{2}{*}{ Subject } & \multicolumn{2}{|c|}{$\begin{array}{c}\text { NBT tests* } \\
\text { PMA-stimulated (\%) }\end{array}$} & \multicolumn{2}{|c|}{$\begin{array}{c}\text { Intact cell cytochrome } \\
b_{558} \text { spectroscopy }\end{array}$} \\
\hline & Negative & Positive & 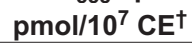 & $\%$ Contro \\
\hline Control & $1 \%$ & 99\% (strong) & 76.1 & $100 \%$ \\
\hline Patient & $0 \%$ & $\begin{array}{c}73 \% \text { (weak) } \\
27 \% \text { (moderate) }\end{array}$ & 11.2 & $14.7 \%$ \\
\hline Father & $0 \%$ & $100 \%$ (strong) & 72.9 & $96 \%$ \\
\hline Mother & $0 \%$ & $\begin{array}{l}59 \% \text { (strong) } \\
41 \% \text { (weak) }\end{array}$ & 59.4 & $78 \%$ \\
\hline Brother & $0 \%$ & $100 \%$ (strong) & 91.2 & $120 \%$ \\
\hline Sister & $0 \%$ & $100 \%$ (strong) & 76.8 & $101 \%$ \\
\hline
\end{tabular}

${ }^{*}$ Note subpopulations of cells in the patient and his mother; ${ }^{\dagger}$ Normal values $8 \%$ to $100 \%$ (based on reference 9). CE Cell equivalents; PMA Phorbol 12myristate 13-acetate

cytochrome $b$ deficiency. The remaining 35\% of patients with CGD have autosomal recessive inheritance, usually with intact levels of cytochrome $b$ in their neutrophils. The most common defect among this group is a deficiency of the $47 \mathrm{kDa}$ cytosolic component (8).

We believe that the neutrophil defect in our patient was transmitted in an X-linked recessive fashion. The carrier status of his mother was demonstrated via specialized neutrophil function studies, which found two subsets of NBTpositive cells, one that was strongly positive and comparable with the control, and a second that was weakly positive and comparable with the patient's weakly NBT-positive cells. Our patient was classified as having type IVA CGD, an extremely rare form of the disease (8), based on normal levels of cytochrome $b$ and X-linked mode of inheritance. NBT reduction is abnormal and there is failure to generate superoxide anions, as in other forms of CGD. In type IVA, however, $80 \%$ to $100 \%$ of cells may be weakly NBT-positive (8). This may explain why the initial NBT test was reported as normal.

CGD is usually recognized during infancy and childhood. However, diagnosis may be delayed until adolescence or adulthood if significant infections have not occurred (10). The small amount of superoxide formation by neutrophils in milder forms of CGD may be sufficient to prevent some episodes of acute infections. Curnutte (8) has observed that gastrointestinal symptoms predominate in patients with milder neutrophil dysfunction and consequently fewer septic complications. Another disorder associated with impaired neutrophil function, glycogen storage disease type $\mathrm{Ib}$, in which glucose-6-phosphate is not transported into the endoplasmic reticulum by glucose-6-phosphate translocase T1, results in impaired gluconeogenesis, fasting hypoglycemia, hepatomegaly, lactic acidosis, hyperlipidemia and hyperuricemia. This disorder has also been associated with an IBD-like picture $(6,7)$. The phagocytic abnormality in this condition probably involves impaired oxidative metabolism and reduced chemotaxis. As in CGD, recurrent pyogenic infections also occur. 
Superoxide anion production by PMA-stimulated Crohn's disease neutrophils has been reported to be significantly lower than by normal neutrophils (11). This suggests that alterations in neutrophil function may be implicated in IBD pathogenesis.

The gastrointestinal tract can be involved in CGD (10). Hepatic abscess has been the most commonly reported gastrointestinal complication of CGD, presenting with fever, right upper quadrant pain, hepatomegaly, leukocytosis and elevation of alkaline phosphatase. However, bilirubin and aminotransferases are frequently normal (12). Our patient exhibited granulomata in his liver, accompanied by extensive fibrosis with no abnormality of aminotransferases, alkaline phosphatase or bilirubin. The presence of granulomata suggests present or past infection in the liver. Our patient complained of occasional nocturnal pruritus with episodes of abdominal pain. The presence of large lymph nodes in close proximity to the bile duct system suggests the possibility of intermittent biliary obstruction. CT images suggestive of a mass anterior to the liver possibly extending to the mediastinum were not confirmed in the exploratory laparotomy. We do not have an explanation for this finding. We speculate that local inflammation and fibrosis may have contributed to create the impression of a prehepatic mass.

In patients with CGD, esophagitis (both primary and secondary to candida infection), esophageal dysfunction, esophageal stricture, obstruction secondary to inflammatory masses, granulomatous inflammation of the gastric antrum with stenosis, pneumatosis intestinalis, relapsing Salmonella enteritidis and rectal abscesses have been reported (3,12-15). In addition, enteritis and colitis resembling Crohn's disease have been described in patients with previously documented CGD $(1,4)$. There is, however, only one previous report similar to our case, of an 11-year-old boy whose initial presentation of CGD was compatible with IBD (5). The colonic biopsies in our patient showed moderate inflammation with occasional pigmented histiocytes. These cells were also present in bone marrow, liver, lymph nodes and small intestine. It has been suggested that the presence of pigmented lipidladen histiocytes in small bowel biopsies should prompt the investigation of neutrophil function (3). In our patient the

\section{REFERENCES}

1. Werlin SL, Chusid MJ, Caya J, Oechler HW. Colitis in chronic granulomatous disease. Gastroenterology 1982;82:328-31.

2. Fisher JE, Khan AR, Heitlinger L, Allen J, Afshani E. Chronic granulomatous disease of childhood with acute ulcerative colitis. Pediatr Pathol 1987;7:91-6.

3. Ament ME, Ochs HD. Gastrointestinal manifestations of chronic granulomatous disease. N Engl J Med 1973;288:382-7.

4. Sty JR, Chusid MJ, Babbitt DP, Werlin S. Involvement of the colon in chronic granulomatous disease of childhood. Radiology 1979;132:618.

5. Lindahl JA, Williams FH, Newman SL. Small bowel obstruction in chronic granulomatous disease. J Pediatr Gastroenterol Nutr 1984;4:637-40.

6. Roe TF, Thomas DW, Gilsanz V, Isaacs H, Atkinson JB. Inflammatory bowel disease in glycogen storage disease type Ib. J Pediatr 1986; 109:55-9.

7. Couper R, Kapelushnik J, Griffiths AM. Neutrophil dysfunction in glycogen storage disease Ib: Association with Crohn's-like colitis. Gastroenterology 1991;100:549-54.

8. Curnutte JT. Classification of chronic granulomatous disease. Hematol Oncol Clin North Am 1988;2:241-51.

9. International Chronic Granulomatous Disease Cooperative Study Group. A controlled trial of interferon gamma to prevent presence of these cells in the intestine, liver and lymph nodes was the most important clue to the diagnosis of CGD.

Gamma-interferon has been reported to be of clinical benefit in patients with all subtypes of CGD. In a large controlled trial the reduction in relative risk of serious infection with gamma-interferon was approximately $67 \%$ (9). In contrast to earlier studies there was no correlation between improvement in phagocyte function and clinical benefit. Gamma-interferon may improve immune function by augmenting alternative pathways of the immune system, such as oxygen-independent microbicidal mechanisms, or $\mathrm{T}$ or $\mathrm{B}$ lymphocyte functions, without directly affecting phagocytic NADPH oxidase. Our patient tolerated gamma-interferon therapy well and had a good clinical response, remaining well five years after treatment was instituted.

In patients with severe gastrointestinal manifestations of CGD who are unresponsive to treatment with gammainterferon, it has been recently reported that a short course of intravenous cyclosporine may be of value (16). However, the significant added risk of serious infection in an already immunocompromised individual has to be considered carefully against the potential benefits of this treatment modality.

\section{CONCLUSIONS}

CGD can present initially with a clinical picture suggestive of chronic intestinal inflammation. Therefore, it should be included in the differential diagnosis of atypical IBD, both in children and young adults.

ACKNOWLEDGEMENTS: The author acknowledges the collaboration of the following persons, without whom this paper would not have been possible: Dr Anne M Griffiths, Associate Professor of Pediatrics, Division of Gastroenterology, The Hospital for Sick Children and the University of Toronto, for her critical review of the manuscript; and Dr Ernest Cutz, Professor of Pathology, The Hospital for Sick Children and The University of Toronto, for interpretation and photographs of the biopsy material. Their help and interest is greatly appreciated. This paper was a winning entry in the Inflammatory Bowel Disease Resident Case Study Competition, supported by an educational grant from Astra Pharma Inc.

infection in chronic granulomatous disease. N Engl J Med 1991;324:509-16.

10. Newman SL, Lindahl JA. Chronic granulomatous disease: A model for gastrointestinal manifestations of immunodeficiency. J Clin Gastroenterol 1985;7:470-1.

11. Curran FT, Allan RN, Kleighley MRB. Superoxide production by Crohn's disease neutrophils. Gut 1991;32:399-402.

12. Mulholland MW, Delaney JP, Simmons RL. Gastrointestinal complications of chronic granulomatous disease: Surgical implications. Surgery 1983;94:569-75.

13. Renner WR, Johnson JF, Lichtenstein JE, Kirks DR. Esophageal inflammation and stricture: Complication of chronic granulomatous disease of childhood. Radiology 1991;178:189-91.

14. Safe AF, Maxwell RT, Howard AJ, Garcia RC. Relapsing Salmonella enteritidis infection in a young adult male with chronic granulomatous disease. Postgrad Med J 1991;67:198-201.

15 Kleinman PK, Brill PW, Winchester P. Pneumatosis intestinalis. Its occurrence in the immunologically compromised child. Am J Dis Child 1980;134:1149-51.

16. Rosh JR, Tang HB, Mayer L, Groisman G, Abraham SK, Prince A. Treatment of intractable gastrointestinal manifestations of chronic granulomatous disease with cyclosporine. J Pediatr 1995;126:143-5. 


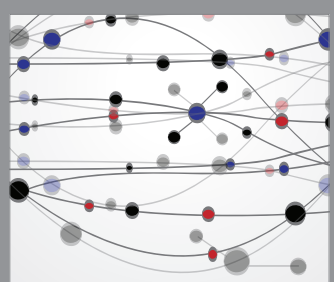

The Scientific World Journal
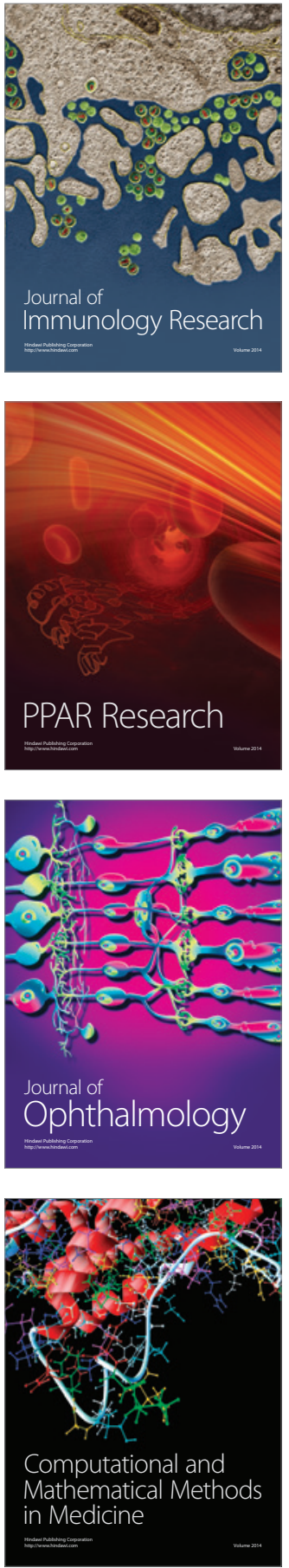

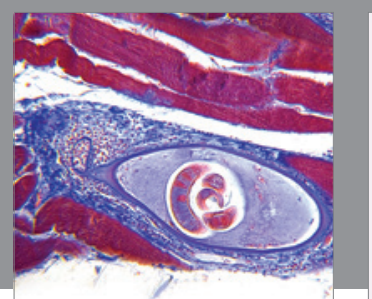

Gastroenterology Research and Practice

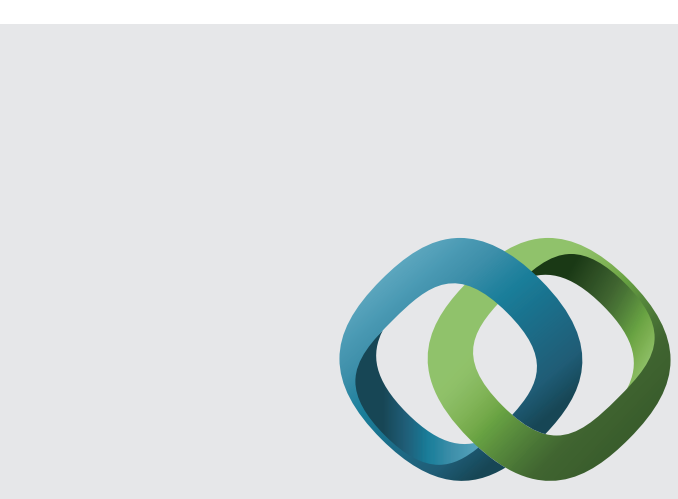

\section{Hindawi}

Submit your manuscripts at

http://www.hindawi.com
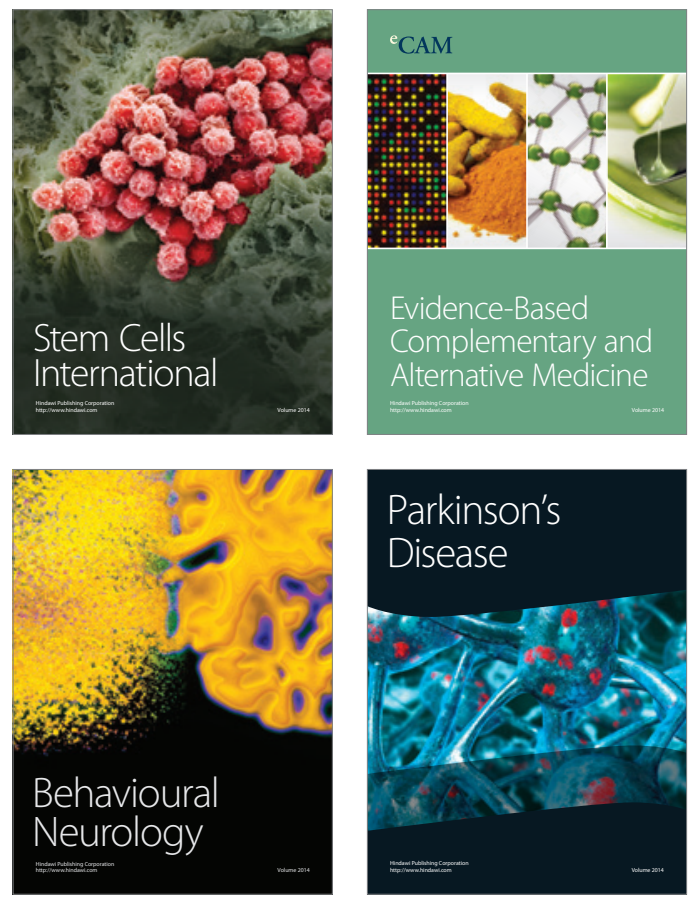
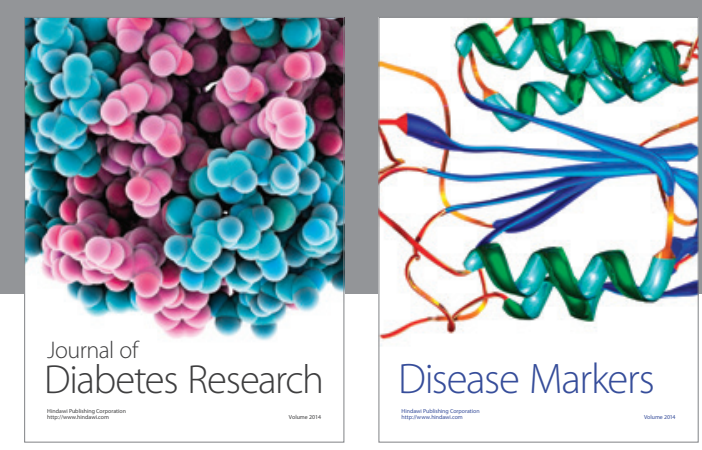

Disease Markers
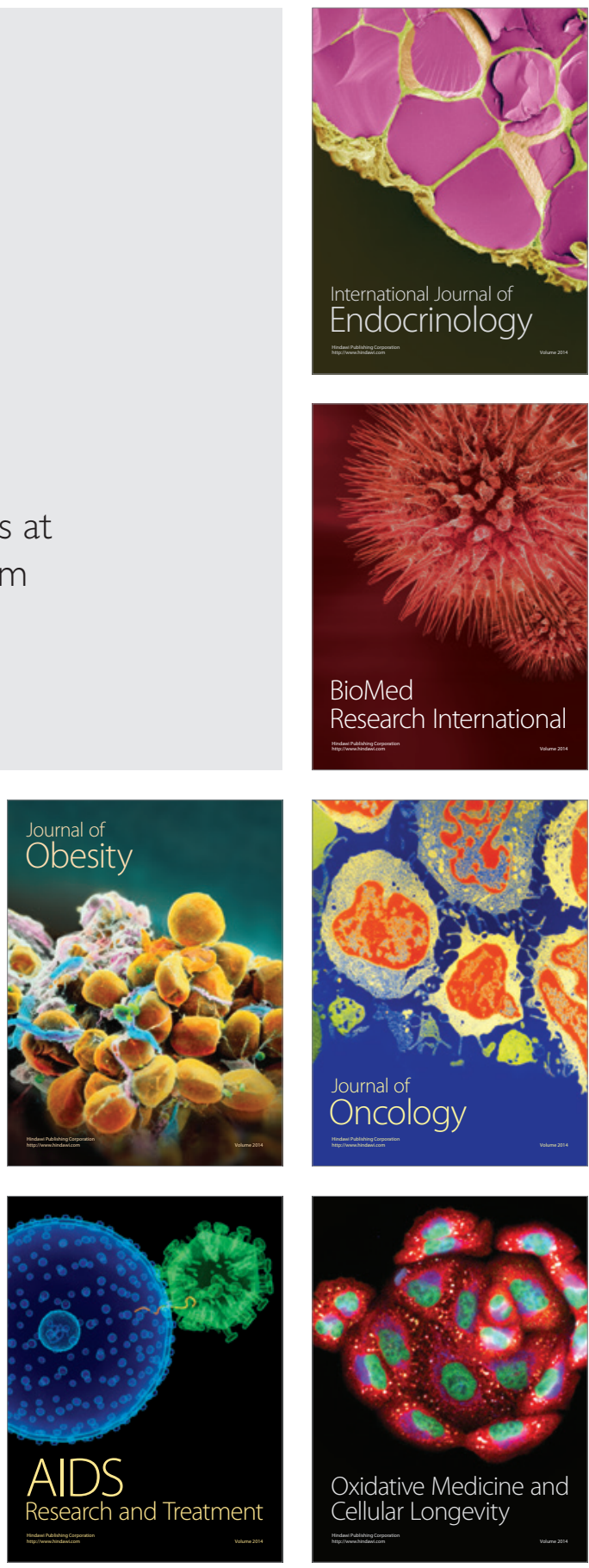